\title{
Perception of Agriculture Students towards the Rural Agricultural Work Experience (RAWE) Programme
}

\author{
Verma Madhuri*, Naberia Seema and V.K. Pyasi \\ Department of Extension Education, College of Agriculture, Jawaharlal Nehru Agricultural \\ University, Adhartal, Jabalpur, 482004, Madhya Pradesh, India \\ *Corresponding author
}

\section{A B S T R A C T}

\begin{tabular}{|l|}
\hline Ke y w o r d s \\
RAWE, \\
Agriculture, \\
Students perception. \\
\hline Article Info \\
\hline $\begin{array}{l}\text { Accepted: } \\
\text { 28 September } 2017 \\
\text { Available Online: } \\
10 \text { October } 2017\end{array}$ \\
\hline
\end{tabular}

The practical knowledge and experience is being realized the backbone for agricultural development process. In this context, a new course, Rural Agriculture Work Experience (RAWE) programme was introduced during final semester of under-graduate curriculum in Agricultural universities. The research study about RAWE was undertaken to study the perception of agriculture students in the college of agriculture, Jabalpur campus. Under expost facto research design and planned to know perception of Agriculture students towards the RAWE programme. All the students who completed RAWE programme in 2016-17 academic year were selected as respondents for the study. Thus, all 118 selected students (52 girls and 66 boys') were interrogated through pre- tested questionnaire schedule to constitute the sample for the investigation. The study revealed that RAWE programme is highly useful in getting familiar with rural life and in understanding village situation and institutions, followed by providing practical training in crop production and improving the communication skills.

\section{Introduction}

The Report of Royal Commission on Agriculture in India [1] stated that complaints were made to them by some cultivators that the training given in the Agricultural College was not sufficiently practical. The practical knowledge and experience is being realized the backbone for agricultural development process. The process of learning in the field situation is superimposed on knowledge acquired in the classroom situation [2]. Considering the importance of practical knowledge in the real life situation, different committees (ICAR Review Committee, 1979; Deans Committee, 1981) suggested the linkage of agricultural education with actual farming situations [3]. In this context, a new course, Rural Agriculture Work Experience (RAWE) programme was introduced during final semester of undergraduate curriculum in Agricultural universities in India viewed as the best opportunity, which can equip and orient the required potential among the students and facilitate them to completely understand the rural scenario. Jawaharlal Nehru Krishi Vishwa Vidyalaya, Jabalpur on the recommendation of Fourth Dean's Committee (ICAR) introduced Rural Agriculture Work Experience programme as an essential requirement for B.Sc. (Ag.) degree with the following objective [4]: 
To understand the rural community life and current situation prevailing in villages with special reference to agriculture and allied enterprises.

To familiarize with the socio-economic conditions of farmers and their problems with reference to agriculture development.

To make students understand farm technologies as adopted by farmers and also to help farmers to prepare sound farm plans matching to available resources.

To facilitate development of communication skills in students through use of extension teaching methods for transfer of technology.

To acquaint the students with the on-going extension \& rural development programmes and to understand the activities of Krishi Vigyan Kendra.

To develop confidence and competence in students for solving teaching problems related to agriculture and allied enterprises.

To develop understanding regarding high-tech agricultural technology and factors affecting in the adoption of modern methods of agriculture by the farmers.

\section{Materials and Methods}

The study was conducted at College of Agriculture, Jabalpur campus purposively because campus has maximum number of students under RAWE programme 2016-17. An ex-post-facto research design is employed as RAWE was already implemented and data was collected from students based on their experience. All the students who completed RAWE programme in 2016-17 academic year were selected as respondents for the study. There were 118 students including 52 girls and 66 boys' students. A well-structured questionnaire was used as an instrument of data collection, including all items pertaining to the specific objectives of the study. The data so collected were classified; tabulated, analyzed and simple percentage, mean and rank order was used to describe the results.

\section{Results and Discussion}

Table 1 depicts that, the rank first was allotted to get familiar with rural people and mean score was recorded as high as 1.94 , it is indicating that RAWE programme has sufficient exposure of students to get familiar with rural people, while Rank II was allotted to understand village situations with mean score 1.88 subsequently rank III was allotted to understand rural institutions with mean score of 1.78 , this shows that RAWE provides sufficient opportunity to understand Village situation and different village institution respectively. Rank IV was allotted to provide practical training in crop production (mean score as 1.71) shows that RAWE programme is useful in providing practical knowledge and skills regarding crop production and protection practices during the entire period of RAWE programme. Rank V was allotted to improve communication skills (mean score 1.69) followed by Rank VI which was allotted to understand cropping pattern of community with mean score 1.66.

Rank VII was allotted to improve diagnostic skills (mean score 1.65) and Rank VIII was allotted to understand adoption pattern and adoption gap with mean score 1.61. To improve leadership qualities was given rank IX as mean score was 1.54. Rank $X$ was allotted to understand the socio economic condition of farmers with mean score 1.50. RAWE provides opportunities to meet role model in agriculture to increase confidence given rank XI as mean score was 1.46. It provides opportunity to work with various agriculture institutions, it developed 
confidence and professional competence to solve field problem and to get acquaint with ongoing TOT programme of agriculture gained ranks XII, XIII and XIV respectively with the respective mean scores $1.44,1.40$, and 1.37 .

Table.1 Perception of participants towards the RAWE programme

\begin{tabular}{|c|l|c|c|}
\hline \multicolumn{3}{|c|}{ INDEX } & \multicolumn{1}{|c|}{ Role of RAWE programme } \\
\hline S. No. & \multicolumn{1}{|c|}{ Mean score } & Rank \\
\hline 1. & To get familiar with rural life & 1.94 & I \\
\hline 2. & To understand village situations & 1.88 & II \\
\hline 3. & To understand rural institutions & 1.78 & III \\
\hline 4. & To understand the socio economic condition of farmers & 1.50 & X \\
\hline 5. & To understand cropping pattern of community & 1.66 & VI \\
\hline 6. & To understand adoption pattern and adoption gap & 1.61 & VIII \\
\hline 7. & To improve diagnostic skills & 1.65 & VII \\
\hline 8. & To provide practical training in crop production & 1.69 & IV \\
\hline 9. & It improves communication skill & 1.46 & XI \\
\hline 10. & $\begin{array}{l}\text { It provides opportunities to meet role model in agriculture to } \\
\text { increase confidence }\end{array}$ & 1.54 & IX \\
\hline 11. & It has improved leadership qualities & 1.44 & XII \\
\hline 12. & $\begin{array}{l}\text { It provided opportunity to work with various agriculture } \\
\text { institutions }\end{array}$ & 1.37 & XIV \\
\hline 13. & To get acquainted with ongoing TOT programme of agriculture & 1.40 & XIII \\
\hline 14. & $\begin{array}{l}\text { It developed confidence and professional competence to solve } \\
\text { field problem }\end{array}$ & & \\
\hline
\end{tabular}

Table.2 Distribution of RAWE participants on perception towards RAWE programme

\begin{tabular}{|c|c|c|c|}
\hline S. No. & Categories & Frequency & Percentage \\
\hline 1. & Low & 00 & 00.00 \\
\hline 2. & Moderate & 32 & 27.12 \\
\hline 3. & High & 86 & 72.88 \\
\hline \multicolumn{2}{|c|}{ Total } & 118 & 100.00 \\
\hline
\end{tabular}

It can be noted from above findings that to get familiar with rural life was ranked first as most achieve objectives followed by to understand village situation and institutions, to provide practical training in crop production and improves communication skill respectively. Findings find support with the work of Kapri et al., (2016) [5], Kotte (2014) [6], Sanjeev and Gowda (2013) [7] and Antwal et al., (2016 [8]. The possible reason is that RAWE provides sufficient exposure of students to the rural life, provides understanding regarding different village situation and institutions. There will be sufficient activities of practical crop production which provides practical knowledge in the crop production. RAWE programme have enough scope in development of communication skill by conducting group discussion, meetings, in the 
preparation and use of Audio-visual aids etc. At the same time it was weak in providing opportunity to work with various agriculture institutions, in developing confidence and professional competence to solve field problem and to get acquainted with ongoing TOT programme of agriculture [5, 6 \& 7].

The data of the table 2 shows the distribution of RAWE participants, on perception towards the RAWE programme. The data reveals that none of the participants had low perception towards the programme. It is noticeable that a huge percentage of participants had high perception towards the RAWE programme, followed by moderate. The findings are in conformity with Kapri et al., (2016) [5] and Kotte (2014) [6]. This shows that the emphasis given on all the modules of the RAWE curriculum is facilitating the learning of the students and designed RAWE programme had met almost all the needs of the students.

On the basis of above study it can be concluded that RAWE programme is highly useful in getting familiar with rural life and in understanding village situation and institutions, followed by providing practical training in crop production and improving the communication skills. At the same time it was weak in providing opportunity to work with various agriculture institutions, in developing confidence and professional competence to solve field problem and to get acquainted with ongoing TOT programme of agriculture. It is also found that a huge percentage $(72.88 \%)$ of participants had high perception towards the
RAWE programme, followed by moderate (27.12\%). This shows that the emphasis given on all the modules of the RAWE curriculum is facilitating the learning of the students and designed RAWE programme had met almost all the needs of the students.

\section{References}

Anonymous, 1928. The Report of the Royal Commission on Agriculture in India, New Delhi: GOI.

Antwal, P.N., Bhosale P.B. and Bellurkar C.M. 2008. Journal of Dairying, Foods \& Home Science, 27(2), 151 - 153.

Borthakur, S., and Bortamuly D. 2013. Journal of Academia and Industrial Research (JAIR), 2, 382-385.

Kapri Anju, Kurbetta N.C. and Hiremath U.S. 2016. Journal of Agroecology and Natural Resource Management, 3(1), 121-124.

Khare, N.K., and Pyasi V.K. 2013. Manual for Rural Agricultural Work Experience. $\quad D F A / J N K V V / M a n u a l$ RAWE/UG/2013/24. Jawaharlal Nehru krishi Vishwa Vidyalaya, Jabalpur, 55.

Kotte, S., 2014. A study on perception among participants of RAWE programme at J.N.K.V.V., Jabalpur. M.Sc. (Ag.) Thesis (unpublished), JNKVV, Jabalpur.

Kumar, S., and Sharma R.C. 2013. Technoframe-A Journal of Multidisciplinary Advance Research, 2(1), 40-43.

Sanjeev, M.V., and Gowda K.N. 2013. Indian

Research Journal of Extension Education, 13(1), 48-55.

\section{How to cite this article:}

Verma Madhuri, Naberia Seema and Pyasi, V.K. 2017. Perception of Agriculture Students towards the Rural Agricultural Work Experience (RAWE) Programme. Int.J.Curr.Microbiol.App.Sci. 6(10): 3420-3423. doi: https://doi.org/10.20546/ijcmas.2017.610.402 